\title{
From caves to climate: Creating the SISAL global speleothem database
}

\author{
Laia Comas Bru', Y. Burstyn ${ }^{2,3}$ and N. Scroxton ${ }^{4}$ \\ First SISAL meeting, Dublin, Ireland, 21-23 June 2017
}

\begin{abstract}
Speleothem based paleoclimate records have risen in prominence over the last few years as long-term, precisely dated, continental archives of past changes in the hydrological cycle. But these valuable records have yet to make significant contributions to recent big data syntheses. For example, only seven records are included in the standard Palaeoclimate Modelling Intercomparison Project (PMIP) benchmark dataset (Harrison et al. 2014). A synthesis of existing speleothems records has great potential for exploring regional and global-scale past changes in the hydrological cycle, as well as for evaluating the ability of climate models that explicitly simulate water and carbon isotopes to capture hydroclimate variability through data-model comparisons. To address these issues and to increase the impact of speleothem research in general, PAGES' SISAL (Speleothem Isotopes Synthesis and Analysis) working group is creating a systematic global synthesis of speleothem $\delta^{18} \mathrm{O}$ and $\delta^{13} \mathrm{C}$ records (Fig. 1 and Comas Bru et al. 2017).
\end{abstract}

Twenty-three SISAL members (including 12 early-career researchers) met for the first SISAL workshop. The meeting took place at the UCD O'Brien Centre for Science at University College Dublin, Ireland, and was coordinated by Laia Comas Bru (University College Dublin, Ireland) and Sandy Harrison (University of Reading, UK). Over three days, workshop participants established the framework for the SISAL database, discussed potential data analysis projects and added entries to the database. On Day 1, speleothem scientists representing all continents (apart from
Antarctica) presented reviews of speleothem research and existing records in their regions, and climate and karst/speleothem modelers also introduced how the SISAL database could be used by their communities. These presentations were followed by an interactive introduction to the preliminary structure of the database that was prepared in advance of the meeting by SISAL steering committee members. During this working session led by Kamolphat Atsawawaranunt (University of Reading, UK), participants had the opportunity to test the structure and contents of the database by entering individual data sets and raising any questions or issues. Based on this feedback, Day 2 was dedicated to group discussions where workshop participants deliberated issues such as identifying the essential metadata needed for SISAL's purpose, dealing with ambiguous terminology and ensuring that the database includes the key parameters and information required for assessing age models. Further discussions on data collection strategy and forward planning of analyses served to shape the key points for the group's first scientific papers. Day 3 brought the workshop to a close with a recap discussion on the next steps before SISAL's second meeting in September 2017 (Kaushal and Comas Bru 2017) and developing a timeline for the working group's activities.

One important decision made during this three-day workshop was the nomination of "regional coordinators", who will liaise with authors publishing on speleothems from a given region and will be responsible for the initial quality control of records. We are confident this approach will enormously help facilitate data entry and also involve a wider group of scientists in the SISAL project, ensuring its success. A complete list of regional coordinators is available on our webpage.

SISAL welcomes paleoscientists interested in the curation of the database and encourages ideas for big data analyses that can be achieved with this new dataset. Those researchers with data to add to the database are encouraged to contact the regional coordinator for the geographic area of their stalagmite record. The first version of the database closes 31 December 2017. For more information about SISAL and how to get involved, go to http://pastglobalchanges.org/ini/wg/sisal

\section{ACKNOWLEDGEMENTS}

We would like to thank PAGES, European Geosciences Union (EGU), iCRAG (Irish Centre for Research in Applied Geosciences), Geological Survey Ireland, Quaternary Research Association UK and the University of Reading for their financial support.

\section{AFFILIATIONS}

'School of Earth Sciences, University College Dublin, Ireland

${ }^{2}$ Geological Survey of Israel, Jerusalem, Israel

${ }^{3}$ Hebrew University of Jerusalem, Israel

${ }^{4}$ Department of Geosciences, University of

Massachusetts Amherst, USA

\section{CONTACT}

Laia Comas Bru: laia.comasbru@ucd.ie

REFERENCES

Comas Bru L et al. (2017) PAGES Mag 25: 129

Harrison SP et al. (2014) Clim Dyn 43: 671-688

Kaushal N, Comas Bru L (2017) PAGES Mag 25: 157

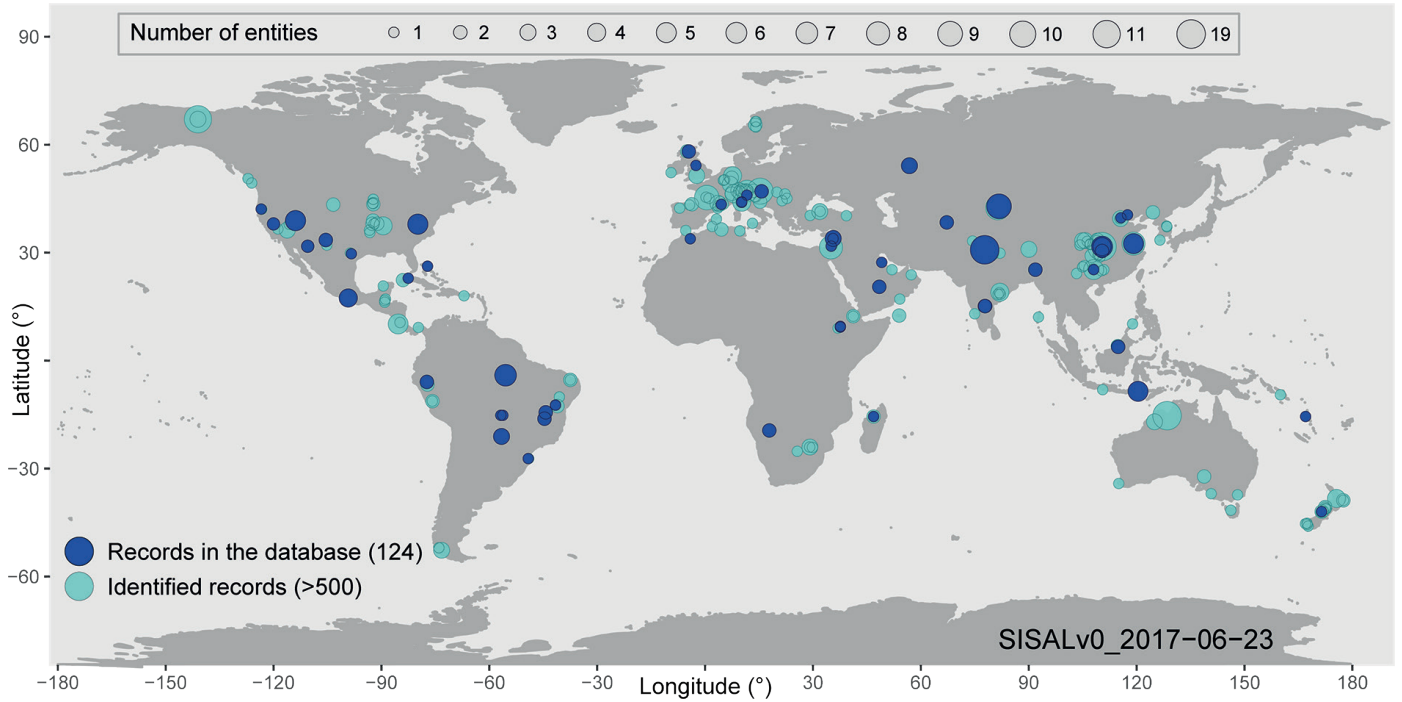

Figure 1: Global map showing the records uploaded to SISAL's database $(n=124$; dark blue) at the end of the workshop versus the $500+$ records identified by SISAL members (cyan). 